\title{
Online Consultation for Family Welfare
}

\author{
Fathul Khair, Elyza Gustri Wahyuni, Sri Kusumadewi \\ \{13523099@students.uii.ac.id ${ }^{1}$, elyza@uii.ac.id ${ }^{2}$, cicie@fti.uii.ac.id ${ }^{3}$ \} \\ Department of Informatics Indonesian Islamic University Yogyakarta, Indonesian
}

\begin{abstract}
Problems that arise in the family if not addressed immediately will cause various impacts, including the impact on the family's lack of harmony and most dangerous, can cause divorce in the household. Household problems can be resolved immediately if the source of the problem is known to find the best solution, but most people cannot solve the problems themselves, so they need the help of others who are experts in their field, one of them is a psychologist. Consultation with a psychologist still has a negative opinion in the community, because some people consider a consultation to be expensive, and time-consuming. From the results of testing the clients and psychologists obtained results that the family problem consultation system online can be a useful forum to facilitate consultation between clients and psychologists without limited geographical problems and time, but it can also be used as a forum to open insight to the public that consultation with psychologists are not expensive and not difficult.
\end{abstract}

Keywords: online consultation, family harmony, household problems.

\section{Introduction}

The household problems are not classified as a new phenomenon in a social life. The high amount of problems in the household's life cause so many aspects to be harmed. One of them is children. If we talk about children, the role of the psychologist is really needed to accompany children in order to stabilize their emotional and to resolve the problem inside the family at the same time. But it is very rare to encounter the patient who wants to show their emotional feelings easily. That fact has become problematic by the psychologist to identify the problem that the patient encountered.

The number of a criminal act and domestic violence caused by lack of self-control over problems in a person and steps that should be done to overcome problems experienced by a person. One that can be done to find out the right self-control is consulting a psychologist, but there are still many assumptions that consulting a psychologist will cost a lot of money, timeconsuming and the assumption that you have mental disorders. So from these assumptions that make people reluctant to communicate with psychologists related to the problems experienced

To overcome these problems, a media is needed to be used as a forum for consultation between psychologists and patients. Where both of them can communicate without face to face, this is very necessary considering the difference in background of patients such as patients and psychologists have their respective activities so to meet face to face is very difficult to do, differences in geographical location that is very likely to occur due to being in the different city from psychologists. As well as the existence of this system can help Psychologists in educating the public about the role of Psychologists and opening up insight to the public who have been 
afraid to consult a Psychologists because of the view that consultation with psychologists is expensive and time-consuming, where it can be managed by this online consultation systems.

In this study, we apply the concept of Electronic Consultation as a solution to solving the problems that we have described initially. In various journals and research, many have used EConsult as a solution to making decisions, increasing the emotional connection between experts and patients and other things [1]. In a research with title "Telemedicine in Plastic Surgery: E-Consult, the attending Surgeon" mentioned that Telemedicine has evolved into a valuable but underused resource for the delivery of health care to patients at a distance, particularly where patient transport is impractical, expensive, complicated, and/or urgent. Today, over 250,000 telemedicine consults are generated annually, involving various specialties in both military and civilian health delivery systems. In this study, they implement E-Consult concept to make a "store-and-forward" solution at UMass Memorial Hospital and Beth Israel Deaconess Hospital whereby the plastic surgery residents who responded to a consult request transmitted digital photographs by means of the Internet to the attending physician on call [2].

\section{THEORETICAL FRAMEWORK}

\subsection{Electronic-Consultation}

The usage of Electronic Consultation is not a new thing for the people out there right now. Emotional Closeness between psychologist and patient is really needed to analyze the problem that the patient suffered. In a Research with title "Online Medical Consultation: A review of literature and practice", it is mentioned that to the tune of $68 \%$ users choose to consult by using Private Portal, and $61 \%$ by using Video Conference, $36 \%$ by using Telephone, $32 \%$ by using email, $25 \%$ by using smartphone, and $7 \%$ users tend to choose public forum [3].

\subsection{Household Problems}

All families face challenges and upheavals during their life cycle from within and without its structure some are expectable strains (brought on by such potential crises as retirement or divorce or remarriage), while others are sudden and untimely (an unforeseen job loss, the unexpected death of a key family member or family friend, a holdup or rape or other violent and life-threating experience, an earthquake or flood) however, not all families react to these potentially disturbing and disruptive events in the same way. Some may experience prolonged distress from which they seem never recover; others suffer less intensely and for shorter periods/ for some families, recovery may come quickly. But they later begin to experience unexpected health problems or somehow never again enjoy life the way they once did [4].

Nevertheless, there is a large number who manage to cope with temporary upheaval or loss, rebound and move on the next challenge. This ability to thrive and maintain relatively stable psychological and physical functioning after extremely aversive experiences, often showing only minor, transient disruption, reveals a great deal about a family's resilience [5].

Few if any families can expect to avoid exposure to stress, loss, or potentially traumatic events at some point in their lifecycle. At the same time, Families have the potential for growth and repair in response to distress, threat, trauma, or crisis, emerging stronger and more resourceful than before [6]. A family as a whole, or one or more of its members, may manifest dysfunctional behavior during periods of persistent stress, but the family process may mediate 
the person's recovery, allowing the family system to rally, buffer stress, reduce the chance of dysfunction, and support optional adaption [4].

\subsection{Likert Scale}

The Likert scale is a bipolar scale method that measures either positive or negative responses to a statement. Four preferred scales are also sometimes used for Likert scale questionnaires that have made people choose one of the poles because the "neutral" option is not available [7].

The next step to get results from each questionnaire question is needs to be calculated by referring to the weight value of each question and the next result can be grouped in value percentage as in Table 1.

Table 1. The Likert Scale Percentage Value

\begin{tabular}{|c|c|c|}
\hline Answer & Weight & Percentage \\
\hline Very Agree & 5 & $80-100 \%$ \\
\hline Agree & 4 & $60-79,99 \%$ \\
\hline Enough & 3 & $40-59,99 \%$ \\
\hline Disagree & 2 & $20-39,99 \%$ \\
\hline Very disagree & 1 & $0-19,99 \%$ \\
\hline
\end{tabular}

\section{SYSTEM ANALYSIS}

The system that we built is a media consultation between psychologists and clients. Which the clients will be able to get advice regarding the problems they face. in this system, there are 3 main menu items, live chat-based consultation, case-based consultation and consultation forum between psychologists. All menus are used to overcome the geographical problems of psychologists and clients, the problem of embarrassment in expressing feelings.

The menu for case-based consultations and live chat-based consultations both require 1 point of consultation. The consultation points obtained from proof of payment that confirmed by the admin. any proof of payment confirmed by the admin gets 2 points of consultation which point can be used for 2 consultation menus either case-based consultation or live chatbased consultation.

The consultation system starts from the registration process to get a client account, then the client must make a payment so that the client can do the consultation process with a psychologist either online or live chat and offline or case. After the client payment get verified by the system, the client can choose a psychologist that concern to the problems faced by the client. In addition, the client can also see a biography of the psychologist and a schedule for a psychologist to conduct live consultations.

After the client chooses a psychologist, the live chat and case process can be done, the conditions that apply to live chat are clients and psychologists at the same time must be online, while the case can be done without having to go online. Every time the client makes a case there will be a notification in the psychologist so that soon the client's question will be immediately answered, whereas if the case is felt the client or psychologist has completed the case status can be closed. So if the client wants to consult again with other psychologists or with other problems, the client can process the repayment. 


\subsection{Payment}

Payment is one of the elements needed for the client to carry out the consultation process in this system when the client uploads a payment receipt, the process will be verified by the admin, after that the client will get 2 points that can be used for live chat and case. The flow of business processes for Payment is as shown in Fig 1.

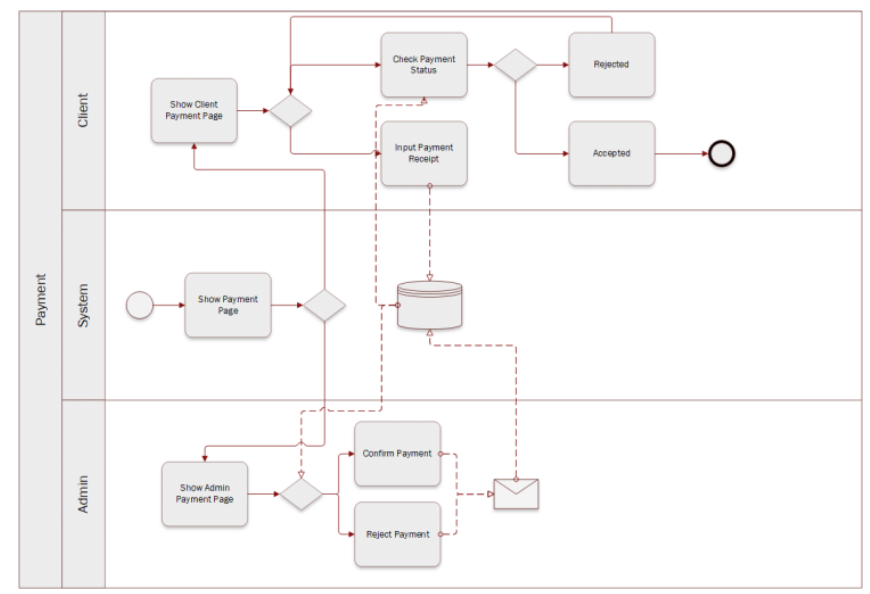

Fig. 1 Business Processes for Payment

\subsection{Create a case}

Case-based consultation (Case) is used to facilitate users in consulting with Psychologists, in this consultation any complaints that require advice from experts will be answered directly by experts based on expert available time. For a case-based consultation, it is not limited by time and it will only be considered complete if the client and psychologist agree that the problem has been resolved. The flow of business processes for creating case is as shown in Figure 2.

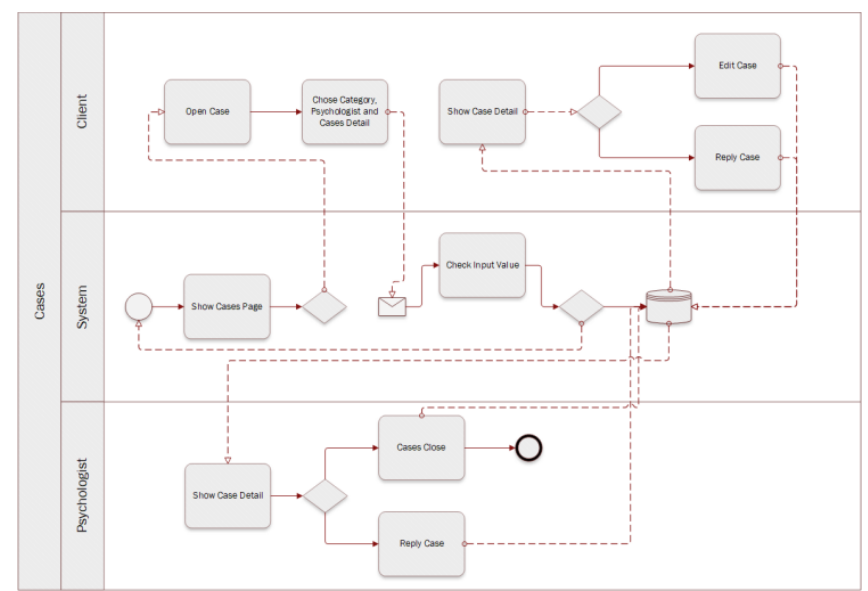

Fig. 2. Business Processes for Create Case 


\subsection{Live Chat}

Live chat consultation is an implementation from e-Consult development by using Realtime chat that both clients need to be online at the same time. This feature answers the problem about Geographical location as a gap between client and psychologist. Live chat is time-based so that when a client or psychologist is not online, the remaining time duration will be saved. Live chat business process as shown in Figure 3.

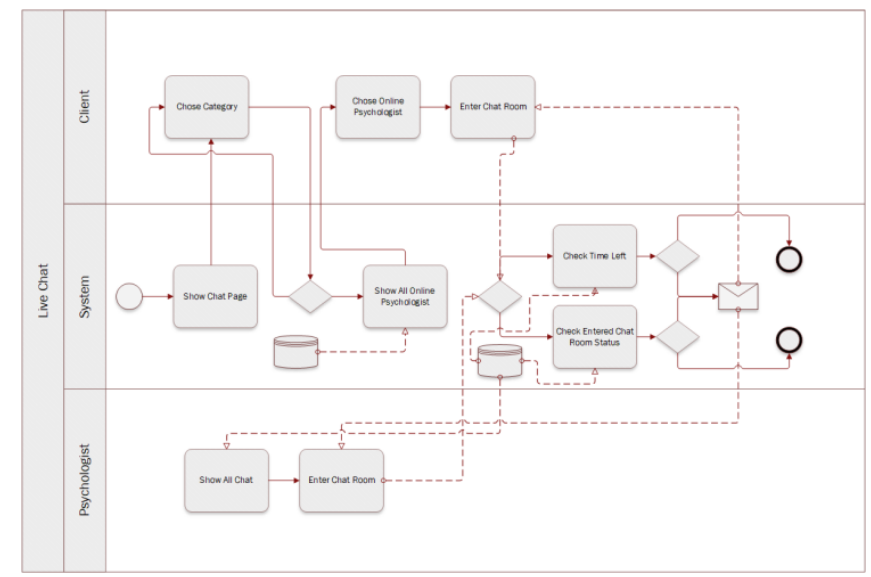

Fig. 3. Business Processes for Live Chat

\subsection{Implementation of system testing}

The implementation of the system test results is done to see the live process consultation that can be done directly with the duration of the time specified by the system. The duration of time will be stopped if the client or psychologist leave the chat room, or the connection is lost, while for data chat can always be seen again both from the client and psychologist. The process of implementing live chat clients and psychologists can be seen in Figure 4.

Another live chat that also has a system is an inter-psychology discussion forum, the goal is to provide facilities to all psychologists who have different fields of expertise from one to another, to be able to discuss the problems experienced by a client, because there is a possibility that a client will consult more than one psychologist with different problems, so to be able to conclude the right solution for the client is to look at all the background problems faced by the client, especially from all discussions with different psychologist. 


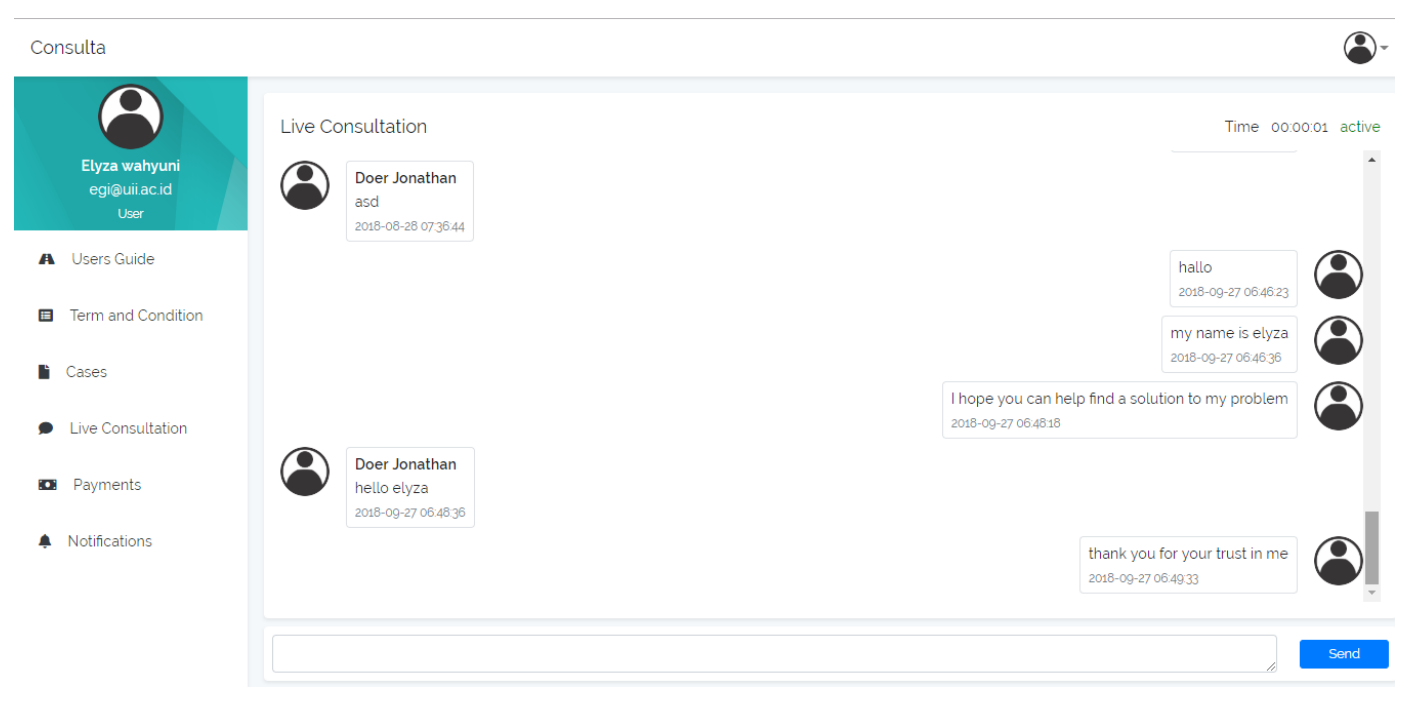

Fig. 4. Live Chat Page for Clients and Psychologists

\section{EXPERIMENTAL RESULT}

User Acceptance Test (UAT) is a testing process conducted by the user intended to produce a document that is used as evidence that the software has been accepted by the user. In this report, the testing process is done with the Likert scale.

There are 2 elements of the system testing examiner, the Expert and the Client, the client who is taken to do the testing is the person who has problems in the household, it can be husband or wife. The first phase of the questionnaire was given to clients who had tried using the system. The questions given to clients are in Table 2.

Table 2. Questionnaire for client

\begin{tabular}{ll}
\hline No & \multicolumn{1}{c}{ Question } \\
\hline 1 & When using the live consultation feature do you feel that you \\
& don't hesitate to consult a psychologist? \\
2 & Can you easily access existing features? \\
3 & Can you easily register into the system? \\
4 & Is the display on the system user-friendly? \\
6 & Can your data change process be fulfilled? \\
7 & Are the menus available to suit your needs? \\
8 & Can you use the functions of each feature? \\
9 & With this system, your time becomes more optimal than you have \\
& to meet directly with a psychologist? \\
10 & Are you categorized as a psychologist easier in determining the \\
& choice to consult?
\end{tabular}


After the questionnaire is filled in by 10 clients, the results are processed using a Likert scale, after calculating the weight of each question, the results of the percentage of each question are as shown in Figure 5.

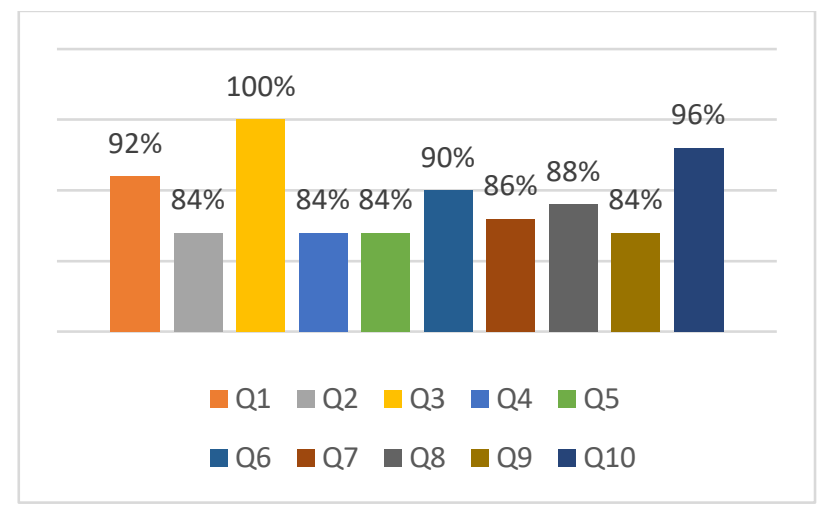

Fig. 5. Percentage Results for Each Question

From Figure 5, it can be concluded that by using this system the client does not hesitate to consult with a psychologist and the client is also comfortable in using the system including the registration process and the process of selecting a psychologist according to the category. UAT results are obtained from 10 clients by $89 \%$ using the Likert scale, then it can be grouped into the very agree category with the system results.

For questions that have been given to the Psychologist, Dr. Hj. Hepi Wahyuningsih, S.Psi., M.Sc, was given after the psychologist finished using/testing the system in a simulation. There are 9 questions to see the results of the system test according to the psychologist into which group the results of this system, and whether the system can be adapted to be applied directly. The following questions are asked to the psychologist in Table 3.

Table 3. Questionnaire for psychologist

\begin{tabular}{ll}
\hline No & \multicolumn{1}{c}{ Question } \\
\hline 1 & Can the system facilitate you in consulting with clients online? \\
2 & Can you easily access existing features? \\
3 & Can you easily register into the system? \\
4 & Is the display on the system user-friendly? \\
5 & Can your data change process be fulfilled? \\
6 & Are the menus available to suit your needs? \\
7 & Can you use the functions of each feature? \\
8 & Whether this system is easier for you to manage time to do online \\
9 & consultations \\
\hline
\end{tabular}

From the answers to questions for psychologists, the results were obtained using a Likert scale of $87 \%$ Very Agree category, which means that psychologists feel helped by the existence of this online consultation system because it can provide the widest possible information for all clients who need a place to consult. 


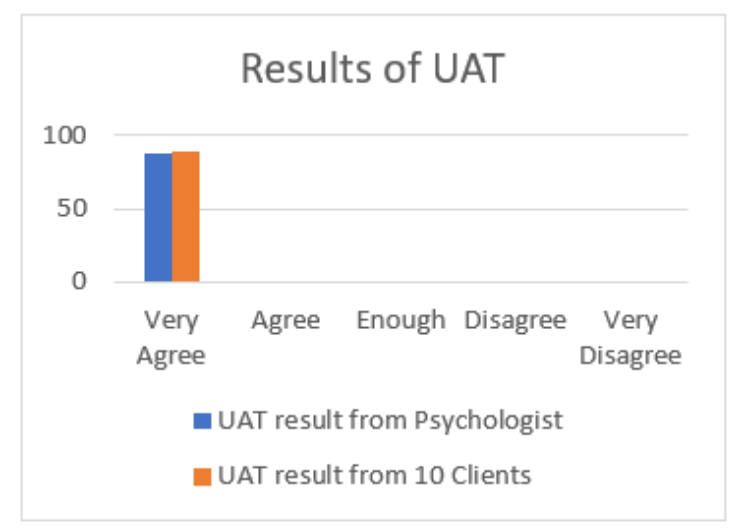

Fig. 6. Results of UAT values from psychologists and clients

From Figure 6 it can be concluded that the result of UAT value from Psychologist and clients falls into the Very Agree category, which means that the client consultation system can work well to facilitate clients and psychologists in communicating online and offline.

\section{CONCLUSION}

The conclusions that can be taken from the results of testing clients and psychologists are: (1) From the results of the UAT test from a sample of 10 clients, the result is $89 \%$, which states that the family problem consultation system online can be a useful forum to facilitate consultation between clients and psychologists without limited geographical problems and time; (2) The results of psychological testing also obtained a result of $87 \%$, which means that the family problem consultation system can help psychologists to make an online consultation system as a forum to open up insight to the public that consultation with psychologists is not expensive and not difficult.

\section{Acknowledgment}

Thank you to the Department of Informatics, Faculty of Industrial Technology, Islamic University of Indonesia, the staff and college teacher. 


\section{References}

[1] K. Horner, W. Ed, and J. Tufano, "Electronic Consultations Between Primary and Specialty Care Clinicians: Early Insights," Commonw. Fund, 2011.

[2] S. A. Pap, E. Lach, and J. Upton, "Telemedicine in plastic surgery: E-consult the attending surgeon," Plast. Reconstr. Surg., 2002.

[3] A. Goswami, P. Jiwane, P. Dandekar, N. Wagh, P. Mahore, and N. A. Ghodichor, "A Review on Literature and Practice for Online Medical Consultation," vol. 7, no. 3, 2017.

[4] I. Goldenberg and H. Goldenberg, "Family Therapy: An Overview.," Fam. Ther. J. Calif. Grad. Sch. Fam. Psychol., 1996.

[5] G. A. Bonanno, "Resilience in the face of potential trauma," Current Directions in Psychological Science. 2005.

[6] F. Walsh, "Family resilience: A framework for clinical practice," Fam. Process, 2003.

[7] A. DeCastellarnau, "A classification of response scale characteristics that affect data quality: a literature review," Qual. Quant., 2018. 